\title{
Positive Mental Imagery in the Intervention of Negative Mood: A Randomized Controlled Trial
}

Wenjing Zhou

Southwest University

\section{Peizhi Li}

Southwest University

Xu Lei

Southwest University

yuan yh ( $\nabla$ yuanyh@swu.edu.cn)

Southwest University https://orcid.org/0000-0002-9038-9296

\section{Research article}

Keywords: Positive mental imagery, Depression\& Anxiety, Vividness, Likelihood

Posted Date: October 19th, 2020

DOI: https://doi.org/10.21203/rs.3.rs-60071/v1

License: (c) (i) This work is licensed under a Creative Commons Attribution 4.0 International License. Read Full License 


\section{Abstract \\ Background}

The aim of this study was to explore the intervention effect of positive mental imagery training on college students' negative emotions in adults with depression trend.

\section{Methods}

A 2 (group: training group, non-training group) and 4 (time: pre-, post-, 1-week follow-up, and 6-week follow-up) mixed design was used in the present study, with the group as between-subjects factor and the time as within-subjects factor. Forty-nine participants with depressive tendency were randomly assigned to either the imagery training group or the non-training group. Except for negative interpretive bias were assessed before and after training, participants' depression and anxiety symptoms, vividness and likelihood of mental imagery were assessed at all four time points.

\section{Results}

Compared to the pre-training, imagery group reported improvement in depression and trait anxiety scores and the likelihood of positive imagery across subsequent three assessments, and showed the improvement in the vividness of positive imagery at post-training. However, there was no significant between-group difference was found in negative interpretation bias.

\section{Conclusions}

The positive mental imagery training could effectively promote negative emotions and anxiety in adults with depression trend after 1-week training, and the effects of mental imagery could at least last for 6weeks, which provides a choice for selfregulation in daily life and is a promising way of mental health care. Often imagine a positive future, at least to some extent, good for our physical and mental health.

\section{Background}

Depression is one of the mood disorders, usually manifests as persistent low mood, pessimism, irritability and a sense of emptiness. It is also accompanied with a variety of cognitive disorders and may prevent patients from involving in daily-life activities (1), about 300 million people around the world is suffering from it (2),and about 95 million people have been diagnosed with depression in China,most of whom do not receive any professional-support (3). In addition, a previous study showed that $20 \%$ of Chinese college students met the diagnostic criteria for mild to major depression (4). Depression increases the global burden in coping with diseases and brings great suffering to patients and their families $(5,6)$. Therefore, a cost-effective and feasible training for individuals with depression is urgently needed.

In recent years, the rise of cognitive bias modification (CBM), which is an imagery-based CBM technique, has demonstrated a promising future for the training on depression (7). Imagery-based CBM technique primarily as an intervention focusing on mental imagery, which was used to selectively target on cognitive bias, leading to a significant reduction in depressive mood and depression-related symptoms (8-12).

Mental imagery refers to the perceptual experience generated by memory in the absence of direct external stimulation (13), like a "weak" form of perception (14),which was often described as seeing with the mind's eye, hearing with the mind's ear and so forth (15). Mental imagery, which can be voluntary or involuntary, usually involves remembering the past or imagining the future, also known as mental time travel (16). With stronger emotional, physical, and behavioral responses, involuntary imagery allows us to remember the past, plan for the future, and make decisions, and thus may have an important influence 
on guiding our thoughts and behaviors (17). In fact, mental imagery has always been regarded as the core part of cognitive behavior theory as well as core training in coping with mental problems. Positive mental imagery training mainly asked participants to repeatedly describe the positive things in their mind, so as to decrease negative emotions. Compared with verbal thoughts, mental imagery enable to evocate stronger emotions(18), and emotion-related processes in the brain may be particularly sensitive to mental imagery (14).

Cognitive vulnerability, such as negative cognitive style is one of the risk factors of depression (19). According to Beck's hypothesis, depression is a biased thinking and emotional disorder. Its emotional, cognitive, behavioral, and biological symptoms are all caused by excessive negative views on the self, the world and the future $(20,21)$. What people were thinking was a better predictor of their happiness than was what they were doing (22). Specifically, depressed individuals have negative biases in many aspects $(23,24)$, it is hard to imagine a positive future, and they are easy to fall into the rumination of thinking, becoming more unhappy and pessimistic about life. In addition, cognition plays a vital role in the development and maintenance of depression and anxiety $(23,25)$. For example, people with depression and anxiety have a negative view on the future and impoverished vividness of mental imagery $(26,27)$. They usually suffer from negative intrusive imagery with the lack of positive mental imagery and have difficulty imagining positive events in the future as well as have negative interpretation bias $(27,28)$.

Positive mental imagery can reduce paranoia and anxiety and enhance positive emotions, self-esteem and self-compassion (29). In addition, mental imagery enables people to have meaningful experiences and improve their mental and physical health (30). In a pilot study conducted in Iran, after 1-week daily mental imagery training treatment-seeking individuals with major depression has showed less depressed emotions and improvements in overall mental health (10). Positive mental imagery training can also enhance vividness of positive imagery, may play a role in improving the intensity and emotional quality of the future imagery activities (31). Study have found that the more vivid participants described the visualizing positive scenarios over the training, the fewer depressive symptoms they would have (9). In a study of bipolar disorders,researchers found that greater vividness of mental imagery during the experimental task was associated with greater amplification of positive moods. Therefore, imagery vividness can be seen as valued observation index in psychological interventions (32). Furthermorelthe likelihood of imagery should also be taken into account in positive mental imagery training $n$ because previous studies have showed that likelihood of positive events is a negative predictor of depression and anxiety $(26,33)$. More specifically, with lower the likelihood of positive events, participants would have greater sense of hopelessness (34). For example, individuals with depression and anxiety rated positive prospective events were less likely to occur and less vivid either (26). Based on the discussion above, we suspected that positive mental imagery training may be a good option to alleviate depressive symptoms. However, most of previous studies were based on western cultural background. The counterparts conducted in the context of non-English-speaking country were not many (10). As far as we know, a recent pilot study of positive mental imagery training conducted in China, by computerizing, found that after four weeks of training, mental imagery improved depressive symptoms, mood, and maladaptive thinking style in Chinese college students (35).

The current study has followed initiatives compared with previous studies: Firstly, since anxiety and depression are linked to cognitive biases on negative materials which affects how people react to past, present and future events (26). Studies have also found that imagining the best self can increase the level of optimism (36). Therefore, the training materials used in this study oriented to imagining a better self in the future which was more self-related. Secondly, in previous positive mental imagery training, participants were often asked to repeatedly practice imagining positive solutions to ambiguous cues, in cultivating a more positive bias in daily life. In the present study, to focus more on positive bias,we specified the positive imaginary scene instead of the ambiguous materials, for participants to imagine. In addition, during the imagery training, participants were asked to write down the details of their imagery scenarios on paper within a specified period of time, so as to reinforce the tendency of using positive mental imagery in their daily life. Lastly, in mental imagery researches, the perspective of the imagery may modulate the emotional influence of the imagery, having received particular attention (17). Some studies found that, field-perspective imagery can evoke more emotional influence than observer perspective imagery 
$(37,38)$. Therefore, the current study controlled the perspective of the imagery, and instructed participants to practice from a field-perspective.

Participants were randomized to receive 1 week of positive mental imagery training or control training conditions. At the baseline (pre-training), the end of training (post-training), and 2 follow-ups (1-week follow-up, 6-week follow-up), participants' depression and anxiety symptoms, negative interpretive bias and vividness and likelihood of mental imagery were assessed.

The aim of the current study was to explore the intervention effect of positive mental imagery training on college students' negative emotions in adults with depression trend, namely, whether 1-week positive mental imagery training is effective in boosting positive effect and easing negative emotions in adults with depressive tendency or not. We hypothesized that: positive mental imagery training would decrease the depression and anxiety symptoms, improve the vividness and likelihood of positive imagery about the future, and the negative interpretive bias might be decreased. In addition, we try to explore the after-effects of 1-week positive mental imagery training.

\section{Methods}

\section{Participants}

In order to recruit qualified participants, online questionnaires were sent out to Southwest University undergraduates and

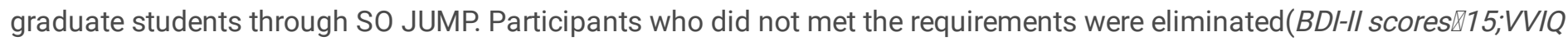
scores $\geq 2$ ) (see Fig. 1 for details), the final number for analysis was 49 (age: $20.88 \pm 2.72$ ). 26 of whom were randomly assigned to imagery group (age: $20.15 \pm 2.19$ ), and 23 were in control group (age: $21.67 \pm 3.04$ ). All participants were righthanded and had normal vision or corrected vision. At the end of the experiment, participants in imagery group were paid 80 $\mathrm{RMB}$, while the control group was paid $40 \mathrm{RMB}$. Demographic information for the participants is presented in Table 1. The current study was approved by the Southwest University Ethics Committee.

Table 1

Descriptive statistics of samples under each condition

\begin{tabular}{|lll|}
\hline & $\begin{array}{l}\text { Intervention group } \\
(\mathbf{n}=\mathbf{2 6})\end{array}$ & $\begin{array}{l}\text { Control group(No-training) } \\
(\mathbf{n}=\mathbf{2 3})\end{array}$ \\
\hline Age (years, $\mathrm{M} \pm \mathrm{SD})$ & $20.15 \pm 2.19$ & $20.41 \pm 2.13$ \\
\hline Gender & & $16(69.57 \%)$ \\
\hline Female & $18(69.23 \%)$ & $7(30.43 \%)$ \\
\hline Male & $8(30.77 \%)$ & \\
\hline
\end{tabular}

\section{Modified CONSORT flow diagram for individual randomized controlled trials of positive mental imagery training.}

\section{Study design}

The present study adopted a mixed design with the time as within-subjects variable (pre-and post- training $₫ 1$-week follow-up $\square$ 6-week follow-up,namely f 1 and $f 2$ ) and the groups as between-subjects variable(training group with imagery-focused positive training $\llbracket$ no-training group with no any training). The dependent variables were state measures of depressive symptoms, anxiety, interpretive bias, and the ability to imagine future. The training group and no-training group had not participated in any similar training before and the interval between the pre- and post-training was 1 week. Following the baseline assessment, participants in the imagery condition received practice in imagery and then completed a session (with 4 trials) of imagery-focused positive training every day in the lab. The training method was paper-and-pencil, and daily training task was different. Participants of non-training group lived as usual after the baseline assessment and were asked to return to the laboratory for assessment only 1 week after. 
Depression and anxiety symptoms, interpretation bias, the ability to imagine future were measured before and after the 1week training. Depression and anxiety symptoms, the ability to imagine future were measured again at 1-week and 6-week follow-up after the training.

\section{Measurements}

Vividness of Visual Imagery Questionnaire, (VVIQ) (39) VVIQ has 16 items, using a 5-point scale, ranging from 1 (no image at all) to 5(image clear and vivid as a perception). VVIQ is one of the most common tools to measure how vividly degree of a visual imagine people can create in their mind, where participants were asked to envision four different scenes (e.g. The colors and shapes of the trees." (39). Higher total scores of VVIQ show vivid imagery. In the study, VVIQ was used to select out participants with similar imagination at the baseline (score $\geq 2$ ). The VVIQ used in this study has good validity and reliability with the Cronbach's $\mathrm{a}=0.88$.

Beck Depression Inventory-Second Edition (BDI-II) (40). Depressive symptoms within 2 weeks are assessed by BDI-II, which is well established and widely used in the measurement and evaluation of depression. It consists of 21 items, in which each item scores from 0 to 3 for a total of 0 to 63 . Scores are classified as: $0-13$ is minimal depression; $14-19$ is mild depression; 20-28 was moderately depressed, and 29-63 is severely depressed. The Chinese version BDI-II has been widely used to measure the severity of depression in Chinese (41). The BDI-II used in this study has good validity and reliability with the Cronbach's $a=0.79$.

Positive and Negative Affective Scale(PANAS) (42) PANAS is used to measure the intensity positive and negative emotions at present moment,which is a self-reported questionnaire that include two 10-item scales (43). In current study $\square$ a Chinese revised version of PANAS was used (42).It consists of 18 items, divided into two demens positive and negative emotions, which are positive and negative. The Chinese version of PANAS showed good internal consistency $\square a=0.85$ and $a=0.84$, respectively. The internal consistency of the positive and negative affect scales in this study were Cronbach's $a=0.84$ and $a=0.77$, respectively.

State-Trait Anxiety Inventory (STAI) (44) The STAI is a questionnaire consisting of two 20 items in each section. The first 20 items are used to measure state anxiety, and the second 20 items are used to measure trait anxiety. Respondents rated the items on a 4-point Likert scale (0 represents "almost never" to 4 represents "always"). The trait measure with good validity and reliability, Cronbach's $\mathrm{a}=0.72$.

Scrambled Sentences Test (SST) (45). This is a paper-based test, developed to measure the implicit interpretation bias of depressed individuals. Before the test, participants were presented with 4 digits and asked to remember them. Then, within 4 minutes, they were asked to use scrambled words (e.g. I, many, friends, have, mistakes) used to construct a complete sentence, which could contains either negative (e.g. I have many mistakes) or positive (e.g. I have many friends) information. The sentence with negative valence is recorded as 1 point, while the one with positive valence is not scored. The final negative cognition score is the proportion of the number of negative sentence in all the sentences. In this study, all test materials were translated into Chinese with good validity and reliability, Cronbach's $a=0.82$.

Prospective Imagery Task (PIT) (46) The PIT test is used to measure participants' ability to imagine future events and their attitudes towards the future. This paper-based test included both positive and negative events (10 items for each, e.g. positive: I will get good grades;negative $\mathrm{II}$ will have an argument with a friend). Participants required to imagine from a field perspective, and the vividness of the event and the likelihood of the event were rated at 7-points Likert scale [Vividness $\square$ from 1 (no image at all) to 7 (very vivid) $\square$ likelihood $\mathbb{1}$ (not at all likely to occur) to 7 (extremely likely to occur)]. Since current study is future-oriented, in order to control participants' differences in their definition of "the future", the study added an evaluation on the length of time before the future come. (e.g. When do you think this will happen ? A week later, A year later, or 3-5 years later). The scale is divided into three sub-scales, and the average score for positive and negative items is calculated respectively. The internal consistency of the different subscales affect scales in PIT were Cronbach's $a=0.79, a=0.80$ and, $a$ $=0.82$, respectively. 


\section{Positive imagery training}

Before the formal training, a questionnaire was designed to collect the life events of non-participants and sent out through internet. A life-event library for the formal experiment was therefore established. A total 828 life events were collected, among which, 747 repeated events were eliminated, and 28 events close to participants' daily life were selected. And each life event was further processed into a simple sentence(e.g. Run into an old friend who I haven't seen for many years, feeling very happy).

When the participants arrived at the laboratory, they were first explained what were mental imagery and field-perspective imagery, and were asked to imagine from a field-perspective in the following training (as if actively involved and seeing it through their own eyes) (47). Then, participants were given an introduction on mental imagery and asked to practice in generating mental imagery, with guidance on how to use it from the researcher (e.g., cutting a lemon. First imagine a lemon, imagine the color and shape of the lemon; second,imagine holding a knife in your hand, you cut the lemon, and can smell the taste of the lemon; Lastly [imagine you pick up the cut lemon, look it up closely, squeeze it with your hands so the lemon juice splashes into your eyes \you feel a little sting). After participants completed the practice session, the formal training started, which consisted of four positive events. Participants were asked to imagine the process of the event in a field-perspective and write it down with as many details as possible. In all sessions, participants were asked to rate 'How vividly degree of imagining the described scenario could you? ', from 1 (not at all vivid) to 7 (extremely vivid); 'How difficult of imagining the described scenario could you?', from 1 (very difficult) to 7 (very easy); 'how pleasure would you be if the described scenario come true?', from 1 (not at all) to 7(very pleasant) after each trial. All tasks were performed at the behavior- observation lab, last for approximately 30 minutes, with 1-2 minutes of rest between each training session.

\section{Procedure}

Participants who met the requirements were randomly assigned to either the training group or the non-training group. Participants in the training group were invited to participate in seven-day positive mental imagery training. When they arrived at the lab, they were instructed to complete a pre-training questionnaire,in the order of "BDI-II -PANAS-STAI-T-SST-PIT", and then began the training. After 1 week training, completed a post-training questionnaire in the same order. Participants in nontraining group only need to come to the lab at the first day to complete pre-training and come back to complete the assessment (post-training) 1 week later, in the same order. After post-training, all participants requested to complete online questionnaires at home for 1-week follow-up\6-week follow-up (See Fig. 2 for the process).

\section{Statistical Analysis}

Repeated-measures ANOVAs were conducted to assess the effect of training and follow-up. First of all, to explore training effect,a two-way repeated-measures ANOVA was used to examine the change differences between target variables across the two time-points between two groups, in which group was between-factor (training group vs. no-training group) and time was within-factor (pre-, post-training) after the formal training. Secondly, $4 \times 2$ mixed model ANOVA was conducted on the followup effect, with time (pre- - post $-\llbracket f 10 \mathrm{f} 2$ ) as the within-subject factor and group (training vs. no-training group) as betweensubject factors. These statistical analyses were carried out by IBM SPSS Statistics 22. The $p$-values were adjusted for sphericity using the Greenhouse-Geisser method. Post-hoc t-tests used Bonferroni adjustments for multiple comparisons.

\section{Results}

\section{Manipulation Check}

There was no significant difference in pleasure, difficulty, likelihood between the 7-day training,illustrating that the material of daily training was homogeneous. Table 4 shows the descriptive statistics of the imagery group's one-week training materials. 
Table 2

The descriptive statistics of the imagery group's training material for one week.

\begin{tabular}{|llllllll|}
\hline Variable $(M \pm S D)$ & Day 1 & Days 2 & Days 3 & Days 4 & Days5 & Days6 & Days 7 \\
\hline Pleasure & $5.47 \pm 0.80$ & $5.57 \pm 0.72$ & $5.82 \pm 0.50$ & $5.68 \pm 0.69$ & $5.77 \pm 0.54$ & $5.91 \pm 0.68$ & $5.87 \pm 0.57$ \\
\hline Difficulty & $5.20 \pm 0.97$ & $5.02 \pm 0.6$ & $4.82 \pm 0.86$ & $4.94 \pm 0.85$ & $5.03 \pm 0.79$ & $5.32 \pm 0.85$ & $5.32 \pm 0.73$ \\
\hline Likelihood & $4.94 \pm 1.32$ & $4.51 \pm 0.58$ & $4.51 \pm 1.10$ & $4.87 \pm 0.87$ & $5.17 \pm 0.80$ & $5.66 \pm 0.74$ & $5.25 \pm 0.70$ \\
\hline
\end{tabular}

All participants completed the post-training evaluation, and there was no significant difference in the follow-up loss rate between the training group and no-training group. Table 3 shows the correlations between baseline measures.

Table 3

Correlations between participant characteristics and outcome measures at baseline

\begin{tabular}{|c|c|c|c|c|c|c|c|c|c|c|c|}
\hline Measure & 1 & 2 & 3 & 4 & 5 & 6 & 7 & 8 & 9 & 10 & 11 \\
\hline 1BDI- II & - & & & & & & & & & & \\
\hline $\begin{array}{l}\text { 2PANAS- } \\
\mathrm{P}\end{array}$ & $-3.71^{\star \star}$ & - & & & & & & & & & \\
\hline $\begin{array}{l}\text { 3PANAS- } \\
\mathrm{N}\end{array}$ & $0.421^{\star \star}$ & -0.168 & - & & & & & & & & \\
\hline 4STAI-T & $0.467 * \star$ & $-0.522^{\star \star}$ & $0.518 * *$ & - & & & & & & & \\
\hline 5SST & $0.385^{\star \star}$ & $-0.422^{\star \star}$ & 0.052 & -0.264 & - & & & & & & \\
\hline 6PIT-P-V & 0.160 & -0.089 & 0.105 & 0.011 & -0.09 & - & & & & & \\
\hline 7PIT-N-V & -0.002 & 0.156 & $0.317 *$ & 0.012 & 0.047 & -0.051 & - & & & & \\
\hline 8PIT-P-L & -0.237 & 0.501 ** & -0.050 & $-0.375^{\star \star}$ & -0.042 & 0.018 & $0.340 *$ & - & & & \\
\hline 9PIT-N-L & 0.056 & 0.012 & 0.208 & -0.020 & 0.082 & 0.531 ** & -0.161 & 0.116 & - & & \\
\hline $\begin{array}{l}\text { 10PIT-P- } \\
T_{T}\end{array}$ & 0.238 & -0.207 & 0.099 & 0.263 & -0.503 & 0.072 & $-0.321^{*}$ & 0.248 & 0.131 & - & \\
\hline $\begin{array}{l}11 \text { PIT-N- } \\
T\end{array}$ & -0.027 & 0.031 & -0.151 & 0.034 & 0.021 & -0.080 & 0.212 & -0.222 & $0.335^{\star}$ & $-0.337 *$ & - \\
\hline
\end{tabular}

The descriptive statistics and statistical analysis results of all measurements for two groups at different time are shown in Table 4. 
Table 4

Results at pre-training, post-training, and follow-up across conditions

\begin{tabular}{|c|c|c|c|c|}
\hline & $\begin{array}{l}\text { Pre-(Pre- } \\
\text { training) }\end{array}$ & $\begin{array}{l}\text { Post-(1 week after pre- } \\
\text { training) }\end{array}$ & $\begin{array}{l}\text { F-1 ( } 1 \text { week after post- } \\
\text { training) }\end{array}$ & $\begin{array}{l}\text { F-2 ( } 6 \text { weeks after post- } \\
\text { training) }\end{array}$ \\
\hline \multicolumn{5}{|l|}{ BDI-II*** } \\
\hline $\begin{array}{l}\text { Training } \\
\text { group }\end{array}$ & $19.50 \pm 5.56$ & $14.58 \pm 5.40^{\star \star \star}$ & $13.00 \pm 9.08^{\star \star \star}$ & $12.74 \pm 7.36^{\star \star \star \star}$ \\
\hline $\begin{array}{l}\text { No-training } \\
\text { group }\end{array}$ & $17.74 \pm 5.70$ & $19.00 \pm 5.62$ & $16.30 \pm 9.22$ & $14.74 \pm 6.41^{\star \star *}$ \\
\hline \multicolumn{5}{|l|}{ PANAS - $P * \star$} \\
\hline $\begin{array}{l}\text { Training } \\
\text { group }\end{array}$ & $23.04 \pm 6.06$ & $26.00 \pm 7.01$ * & $25.28 \pm 7.49$ & $25.48 \pm 7.40$ \\
\hline $\begin{array}{l}\text { No-training } \\
\text { group }\end{array}$ & $25.74 \pm 6.56$ & $22.43 \pm 6.24^{\star}$ & $25.60 \pm 9.05$ & $25.58 \pm 8.26$ \\
\hline \multicolumn{5}{|l|}{ PANAS-N } \\
\hline $\begin{array}{l}\text { Training } \\
\text { group }\end{array}$ & $22.65 \pm 6.61$ & $20.69 \pm 6.46^{\star \star}$ & $21.48 \pm 7.61$ & $22.35 \pm 7.98$ \\
\hline $\begin{array}{l}\text { No-training } \\
\text { group }\end{array}$ & $22.65 \pm 6.61$ & $21.30 \pm 7.36$ & $22.25 \pm 7.43$ & $24.11 \pm 6.19$ \\
\hline \multicolumn{5}{|l|}{ STAI-T* } \\
\hline $\begin{array}{l}\text { Training } \\
\text { group }\end{array}$ & $53.46 \pm 7.82$ & $51.38 \pm 7.15$ & $48.48 \pm 6.39$ & $48.43 \pm 7.49$ \\
\hline $\begin{array}{l}\text { No-training } \\
\text { group }\end{array}$ & $49.96 \pm 8.18$ & $53.57 \pm 7.23^{\star}$ & $51.05 \pm 6.13$ & $52.05 \pm 9.03$ \\
\hline \multicolumn{5}{|l|}{ SST } \\
\hline $\begin{array}{l}\text { Training } \\
\text { group }\end{array}$ & $8.00 \pm 3.59$ & $7.42 \pm 3.15$ & - & - \\
\hline $\begin{array}{l}\text { No-training } \\
\text { group }\end{array}$ & $6.96 \pm 2.92$ & $7.35 \pm 4.14$ & - & - \\
\hline \multicolumn{5}{|l|}{ PIT-P-V } \\
\hline $\begin{array}{l}\text { Training } \\
\text { group }\end{array}$ & $35.31 \pm 5.51$ & $39.58 \pm 5.57$ & $38.05 \pm 5.01$ & $38.50 \pm 5.28$ \\
\hline $\begin{array}{l}\text { No-training } \\
\text { group }\end{array}$ & $37.17 \pm 6.91$ & $36.91 \pm 5.66$ & $36.73 \pm 5.27$ & $35.15 \pm 3.56$ \\
\hline \multicolumn{5}{|l|}{ PIT-N-V } \\
\hline $\begin{array}{l}\text { Training } \\
\text { group }\end{array}$ & $34.62 \pm 4.90$ & $37.27 \pm 6.14$ & $35.77 \pm 4.55$ & $35.82 \pm 5.86$ \\
\hline $\begin{array}{l}\text { No-training } \\
\text { group }\end{array}$ & $33.43 \pm 5.08$ & $34.17 \pm 6.62$ & $33.99 \pm 5.62$ & $33.12 \pm 4.74$ \\
\hline
\end{tabular}

Note: BDI- II - Beck's Depression Inventory- Second Edition; PANAS - Positive and Negative Affect Scale, -P - Positive, -N - Negative; STAI-T - Trait Anxiety Inventory; SST- Scrambled Sentences Test;PIT - Prospective Imagery Task, -P Positive,,$-V$ - Vividness, $-L$ - Likelihood, -T -Sense of Time.

${ }^{*} \mathrm{p}<0.05^{* \star} \mathrm{p}<0.01{ }^{\star \star *} \mathrm{p}<0.001$ 


\begin{tabular}{|c|c|c|c|c|}
\hline & $\begin{array}{l}\text { Pre-(Pre- } \\
\text { training) }\end{array}$ & $\begin{array}{l}\text { Post-(1 week after pre- } \\
\text { training) }\end{array}$ & $\begin{array}{l}\text { F-1 ( } 1 \text { week after post- } \\
\text { training) }\end{array}$ & $\begin{array}{l}\text { F-2 ( } 6 \text { weeks after post- } \\
\text { training) }\end{array}$ \\
\hline $\begin{array}{l}\text { Training } \\
\text { group }\end{array}$ & $31.23 \pm 4.63$ & $35.23 \pm 5.31^{\star \star \star}$ & $33.67 \pm 5.86^{\star \star}$ & $32.67 \pm 4.28^{*}$ \\
\hline $\begin{array}{l}\text { No-training } \\
\text { group }\end{array}$ & $34.78 \pm 5.21$ & $34.83 \pm 4.66$ & $33.64 \pm 5.34$ & $34.35 \pm 4.93$ \\
\hline \multicolumn{5}{|l|}{ PIT- N-L } \\
\hline $\begin{array}{l}\text { Training } \\
\text { group }\end{array}$ & $31.65 \pm 4.56$ & $34.48 \pm 5.49 *$ & $31.58 \pm 4.23$ & $32.49 \pm 4.87$ \\
\hline $\begin{array}{l}\text { No-training } \\
\text { group }\end{array}$ & $30.70 \pm 5.56$ & $31.39 \pm 6.69$ & $30.23 \pm 6.34$ & $29.87 \pm 6.00$ \\
\hline \multicolumn{5}{|l|}{ PIT-P-T } \\
\hline $\begin{array}{l}\text { Training } \\
\text { group }\end{array}$ & $20.40 \pm 3.61$ & $20.48 \pm 1.00$ & $22.12 \pm 3.28$ & $22.32 \pm 3.54$ \\
\hline $\begin{array}{l}\text { No-training } \\
\text { group }\end{array}$ & $18.96 \pm 3.65$ & $19.22 \pm 3.36$ & $20.45 \pm 3.19$ & $20.79 \pm 3.63$ \\
\hline \multicolumn{5}{|l|}{ PIT-N-T } \\
\hline $\begin{array}{l}\text { Training } \\
\text { group }\end{array}$ & $21.25 \pm 3.52$ & $21.81 \pm 3.51$ & $23.39 \pm 3.06$ & $23.00 \pm 3.11$ \\
\hline $\begin{array}{l}\text { No-training } \\
\text { group }\end{array}$ & $22.13 \pm 3.49$ & $22.00 \pm 3.64$ & $22.30 \pm 3.42$ & $22.58 \pm 3.25$ \\
\hline \multicolumn{5}{|c|}{$\begin{array}{l}\text { Note: BDI- II - Beck's Depression Inventory- Second Edition; PANAS - Positive and Negative Affect Scale, -P - Positive, -N } \\
\text { - Negative; STAI-T - Trait Anxiety Inventory; SST- Scrambled Sentences Test;PIT - Prospective Imagery Task, -P - } \\
\text { Positive, -V - Vividness, -L - Likelihood, -T - Sense of Time. }\end{array}$} \\
\hline \multicolumn{5}{|c|}{${ }^{*} \mathrm{p}<0.05^{* *} \mathrm{p}<0.01{ }^{* * *} \mathrm{p}<0.001$} \\
\hline
\end{tabular}

\section{Training effect analysis}

\section{Questionnaire measures}

Repeated-measures ANOVAs were conducted to assess the effect of training on questionnaire measures. There were significant main effects of time or interactions between time $\times$ group across the following measures: BDI-II [Time: F $(1,47)=$ 6.33, $p=0.015, \eta^{2}=0.12 ;$ Time $\times$ Group: $\left.F(1,47)=18.03, p<0.001, \eta^{2}=0.28\right]$;PANAS positive subscale [Time $\times$ Group $\square F(1$, $\left.47)=11.93, p=0.001, \eta^{2}=0.20\right]$ PANAS negative subscale[Time $\left.\mathrm{F}(1,47)=8.00, p=0.007, \eta^{2}=0.15\right] \otimes S T A I-T$ [Time $\times$ Group $\square F$ $\left.(1,47)=6.93, p=0.011, \eta^{2}=0.13\right]$ (see Fig. 3 and Table 4). However,there was no main effects of time or interactions between time $\times$ group on the SST. These significant effects of time and interactions reflected decreased scores on the BDI-IIIM $=4.92$, $S D=1.00, p<0.001$ in training group, PANAS positive subscale $\square M=3.30, S D=1.32, p=0.016$ in no-training group, and increased scores on the PANAS positive subscale $\square \mathrm{M}=-2.96, \mathrm{SD}=1.24, \mathrm{p}=0.021$ in the training group $\square \mathrm{STAl}-\mathrm{T} \square \mathrm{M}=-3.61, \mathrm{SD}=$ $1.57, p=0.026$ in no-training group.

\section{Prospective Imagery Task}

Ratings for positive and negative scenarios were analyzed in separate 2-way ANOVAs across different subscales of PIT, with time and group as factors. Results were as follows: Vividness positive scenarios [Time $\times$ Group: $F(1,47)=3.18 \unrhd p=0.08, \eta^{2}=$

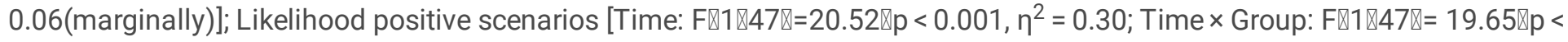
$0.001, \eta^{2}=0.30$ ](see Fig. 3 and Table 4). These significant effects of time and interactions reflected increased scores on the 
vividness positive scenarios $(M=-4.27, S D=1.74, p=0.02)$ and likelihood positive scenarios $\square M=-4.00, S D=6.12, p<0.001$ पwithin training group. Howeverlthere were no main effects of time or interactions between time $\times$ group in time of occurrence.

\section{Follow-up effect analysis}

\section{Questionnaire measures}

Only those who provided follow-up data are included in following analyses, during the follow-up process, 3 (11.54\%) people were lost in training group and 4 (17.39\%) people were lost in no-training group. Finally, 23 people in the training group and 19 people in the no-training group were included.(see Fig. 1).

$4 \times 2$ mixed model ANOVA was conducted on the follow-up. There were significant main effects of time or interactions between time $\times$ group across the following measures: BDI-II [Time: $F(3,120)=10.30, p<0.001, \eta^{2}=0.21$; Time $\times$ Group: $F$ $\left.(3,120)=5.24, p=0.002, \eta^{2}=0.12\right]$;STAI-T [Time $\times$ Group: $F(3,120)=2.69, p=0.005, \eta^{2}=0.06$ ]. These significant effects of time and interactions showed significant decrease scores on BDI-II (training group: pre- to $f 1: M=7.52, S D=1.33, p<0.001$, pre- to $\mathrm{f} 2 \mathrm{M}=6.87, \mathrm{SD}=1.48, \mathrm{p}<0.001$; no-training group: post- to $\mathrm{f} 2 \mathrm{M}=4.90, \mathrm{SD}=1.45, \mathrm{p}=0.002$ ); STAI-T (training group: pre- to $f$ : $M=5.04, S D=1.74, p=0.01$, pre- to $f: M=5.09, S D=2.42, p=0.04$ ) (see Fig. 4 and Table 4).

\section{Prospective Imagery Task}

$4 \times 2$ mixed model ANOVA showed there were significant main effect of time or interaction between time and groups across different subscales of PIT. Vividness [Time $\times$ group : $F(3,120)=2.74, p=0.047, \eta^{2}=0.06$ ], vividness negative scenarios [Time: $F$ $\left.(3,120)=3.21, p=0.03, \eta^{2}=0.07\right]$. The vividness scores were significantly improved at the different time points after

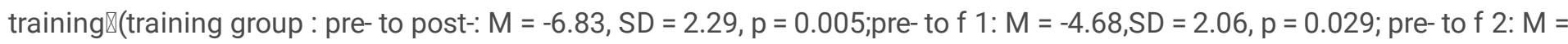
$-5.51, S D=2.20, p=0.027$; no-training group: pre- to f $2: M=-2.95, S D=1.35, p=0.035)$. Likelihood: positive scenarios [Time: $F(3 \rrbracket 120)=3.15 \square p=0.03, \eta^{2}=0.07$; Time $\times$ group: $\left.F(3 \rrbracket 120)=6.39 \square p<0.001, \eta^{2}=0.14\right] ;$ Negative scenarios $[$ Time: $F(3,120)=$ $5.49 \varangle p=0.001, \eta^{2}=0.12$ ]. These significant main effect of time or interaction showed a significant increase on likelihood of training group (pre- to post-: $M=-4.04, S D=0.60, p<0.001$; pre- to $f 1: M=-2.24, S D=0.82, p=0.01$; pre- to $f$ : $M=-1.84, S D=$ $0.80, p=0.03)$. For time of occurrence in positive scenarios, there was only a significant main effect of time $[F(3,120)=6.59$, $\left.p<0.001, \eta^{2}=0.14\right]$ (see Fig. 4 and Table 4).

\section{Discussion}

The present study sought to explore the training effect of positive mental imagery on college students' negative emotions, which conducted in a different way from traditional imagery training (visualize positive future events directly), which is the first laboratory intervention study in China to test the effect of positive mental imagery training on negative mood and anxiety.

As what we predicted,compared to no-training groups, we found that BDI-II scores were reduced in post-training, 1-week followup and 6-week follow-up in training group $\square$ which suggested positive imagery training could help participants lighten their depressive symptoms and such an effect remained for 6 week after the training. Previous studies showed that mental imagery can trigger a range of emotional responses, serving as an "emotional amplifier" (48)【affecting motivation and behaviors. It makes imagery a powerful facilitator in bringing cognitive, affective, and behavioral change in positive way (49) \enhancing the level of anticipated pleasure (50). It tends to evokes stronger subjective emotional responses, compared to those triggered by verbal processing patterns, in both physiological, neurological layer that tend to be stronger than those triggered by (13). Materials used in the study also implied to imagine the best self in the futurelwhich were consisted with the findings of Meevissen' study that imagining one's best self can enhance optimistic level (36), and have stronger positive affect when viewing positive visualized stimuli (51). Therefore, participants in the training group may have more positive moods after positive imagery training. In addition, we found a decrease score of depression in no-training group across through pre-training to follow-up. Overall, the BDI- II scores of two groups were decreasing over time, which manifested by less 
negative emotions. Even though time may heal all wounds, the increase in positive emotions was more pronounced in the training group than in the no-training group.

After the training, the positive emotions that measured by PANAS in the training group were significantly improved, while the positive emotions in the no-training group were decreased, which consistent with previous findings $(8,52)$. The finding indicated that the positive mental imagery effectively improve the emotional state and has an immediate effect on the improvement of negative emotions in the short term.

The trait anxiety score of post-training was increased compared to the pre-training in no-training group, while there was no same effect in training group. Considering that the training began at the beginning of the new semester, with the intervention, participants began to enter into busy study, and the academic pressure led to anxiety, so the anxiety score increased. However, the anxiety score of the training group did not change, which may indicate that the positive mental imagery training played a buffering role on the anxiety state caused by the increased academic pressure, which can help the subjects to relieve anxiety and cope with learning stress. Consistently, anxiety scores decreased significantly in training group during follow-up questionnaires from 1 week to 6 weeks, while no-training group maintained their original high anxiety state. These results further demonstrate the effect of positive imagery on the improvement of anxiety, and demonstrate that positive mental imagery not only has an immediate effect, but also has an after-effect lasting for 6 weeks, which fitted with previous studies, mental imagery could reduce anxiety $(8,10,47)$.

For the imagery vividness, we found that there was a marginally improvement in the vividness of positive from pre- to posttraining within the training group, but the improvement was not found in either 1-week or 6-week follow-up. However, the improvement in the vividness remained the same while the depression scores decreased. The finding suggested that the training was effective in some extent. The ability to vividly imagine possible positive events in one's future has been found associated with higher levels of optimism $(53,54)$. In addition, imagery vividness can predict the degree of reduction in depression symptoms, namely, the more vividly could participants describe mentally visualized positive scenarios, the more positive mood was applicated $(32)$ with fewer depressive symptoms $(9,26)$. Imagery vividness can increases the level of behavioral activation. In the positive imagery condition, more vivid the imagined training scenarios was reported during the training, the level of behavioral activation would increase more, affecting emotional state as result (55). Although in the present study,the increase in different valence of vividness of training group was marginal, the vividness score increase from baseline to follow-up was significant $\square$ and the positive moods showed a tendency to increase in line with vividness.

In addition, we found that there was a significant increase in the likelihood of positive event form pre-training to follow up. Lo 'pez-Pe'rez et al found that likelihood of positive events is a negative predictor of depression and anxiety (33), the lower the likelihood of positive events, the greater sense of hopelessness (34). In fact, depression is often associated with cognitive vulnerability (5), difficulty in imagining a positive future, and low likelihood of future positive events to occur (26). Participants were asked to imagine a positive future and goal in order to increase their positive emotions and reinforce the belief of realizing positive goals, thus increasing the likelihood of taking actions to achieve these goals and thereby elevating their moods (56). Repeating the practice of generating positive mental imagery can promote the activation of self-reported behaviors and enjoyment in the daily life $(50,55,57)$.Therefore, the results of these analyses suggest increase in the likelihood of positive event is consistent with reduced depression tendency and anxiety. After 1-week training, instead of pessimism, participants felt hopefully for the future.

There was no significant difference in interpretation bias between two groups, measured by the Scrambled Sentences Task, which was inconsistent with our hypothesis. The findings are consistent with previous studies $(47,58)$. However, there are some previous studies have found that positive mental imagery training could lead to greater improvements in interpretive bias $(10,59)$. The first reason may be that instead of giving the ambiguous materials, participants were directly given the positive results, actually the process of cognitive training was missed, therefore do not really correct the cognitive bias. As Clarke et al. have argued, the mere act of imagining positive (or negative) events is unlikely to change the interpretation bias, unless emotional valence of the scenarios consistent with the ambiguity task (58). Secondly, participants in our study are 
whose with depressive symptoms but far from clinical level, and maybe only have weak negative cognitive bias, lead to the floor effect for SST score and the positive vividness scores.

There are several limitations for this study. First, most previous studies were conducted on clinically diagnosed patients but participants in this study were non-clinically depressed college students. Second, the sample size of the participants in the study was relative small. Future studies could use as large sample as possible to improve the ecological validity of the experimental results. Third, this study is only a behavioral study, without evidence of electrophysiology or fMRI.

\section{Conclusion}

These results of this study suggest that 1-week training of mental imagery can reduce depressive symptoms, improve mood states, alleviate anxiety and make people feel more confident about the future, and some effects even lasted for 6 weeks. Moreover, positive mental imagery is easy to implement and easy to operate, which provides a choice for self-regulation in daily life and is a promising way of mental health care. Often envision a positive future, at least to some extent, is good for our physical and mental health. Therefore, in our daily life, when we are feeling anxious and depressed,pessimistic about the future, we might as well take some time to separate ourselves from the present and imagine a bright and hopeful future, which will help us to heal the negative emotions in the present and increase our confidence in the future.

\section{Abbreviations}

CBM

cognitive bias modification;

BDI- II

Beck's Depression Inventory- Second Edition;

PANAS

Positive and Negative Affect Scale, $-\mathrm{P}$ - Positive, $-\mathrm{N}$ - Negative;

STAI-T

Trait Anxiety Inventory;

SST

Scrambled Sentences Test;

\section{Declarations}

\section{Ethics approval and consent to participate}

Ethical approval was obtained from the Ethics Committee of Southwest University and all participants provided written informed consent to participate in the study.

\section{Acknowledgements}

This research was supported by the cognitive behavioral laboratory at Southwest University, and by a grant from the Department of Psychology, Southwest University.

\section{Funding}

Funding for the study was provided by the Department of Psychology, Sleep and Neurolmaging Center, Key Laboratory of Cognition and Personality (Ministry of Education), Southwest University. The funding institutions had no role in the design of 
the study and will not have any role during its execution, analyses and interpretation of the data, or the decision to submit the results.

\section{Availability of data and materials}

Data sets used and/or analyzed in the current study are available from corresponding authors.

\section{Authors' contributions}

All authors contributed in designing and performing the study, interpreting the data and approved the final version of the paper. PZL performed the experiment; WJZ contributed significantly to analysis and manuscript preparation; WJZ performed the data analyses and wrote the manuscript; $H Y$ helped perform the analysis with constructive discussions; $X L$ provide financial support.

\section{Consent for publication}

Not applicable.

\section{Competing interests}

The authors declare that they have no competing interests.

\section{Publisher's Note}

Springer Nature remains neutral with regard to jurisdictional claims in published maps and institutional affiliations.

\section{Author details}

${ }^{1}$ Sleep and Neurolmaging Center, Faculty of psychology, Southwest University, Chongqing, China

${ }^{2}$ Key Laboratory of Cognition and Personality (Ministry of Education), School of Psychology, Southwest University, Chongqing, China

\section{References}

1. American Psychiatric Association A. Diagnostic and statistical manual of mental disorders (DSM-5®). New York: American Psychiatric Pub; 2013.

2. World Health Organization W World Health Organization W. Depression. Retrieved from http://www.who.int/news-room/fact-sheets/detail/depression. 2018.

3. people.cn. www.people.com.cn. 2019.

4. Tang F, Byrne M, Qin P. Psychological distress and risk for suicidal behavior among university students in contemporary China. J Affect Disord. 2018;228:101-8.

5. Herrman H, Kieling C, McGorry P, et al. Reducing the global burden of depression: a Lancet-World Psychiatric Association Commission. The Lancet. 2019;393:42-3.

6. Ledford H. Medical research: if depression were cancer. Nature. 2014;515:182-4. 
7. Holmes EA, Craske MG, Graybiel AM. Psychological treatments: a call for mental-health science. Nature. 2014;511:287-9.

8. Holmes EA, Lang TJ, Shah DM. Developing interpretation bias modification as a "cognitive vaccine" for depressed mood: imagining positive events makes you feel better than thinking about them verbally. J Abnorm Psychol. 2009;118:76-88.

9. Blackwell SE, Browning M, Mathews A, et al. Positive Imagery-Based Cognitive Bias Modification as a Web-Based Treatment Tool for Depressed Adults: A Randomized Controlled Trial. Clin Psychol Sci. 2015;3:91-111.

10. Torkan H, Blackwell SE, Holmes EA, et al. Positive Imagery Cognitive Bias Modification in Treatment-Seeking Patients with Major Depression in Iran: A Pilot Study. Cognit Ther Res. 2014;38:132-45.

11. Blackwell SE, Holmes EA. Modifying interpretation and imagination in clinical depression: A single case series using cognitive bias modification. Applied Cognitive Psychology. 2010;24:338-50.

12. Lang TJ, Blackwell SE, Harmer CJ, et al. Cognitive Bias Modification Using Mental Imagery for Depression: Developing a Novel Computerized Intervention to Change Negative Thinking Styles. Eur J Pers. 2012;26:145-57.

13. Ji JL, Heyes SB, MacLeod C, et al. Emotional Mental Imagery as Simulation of Reality: Fear and Beyond-A Tribute to Peter Lang. Behav Ther. 2016;47:702-19.

14. Pearson J, Naselaris T, Holmes EA, et al. Mental Imagery: Functional Mechanisms and Clinical Applications. Trends Cogn Sci. 2015;19:590-602.

15. Kosslyn SM, Ganis G, Thompson WL. Neural foundations of imagery. Nat Rev Neurosci. 2001;2:635-42.

16. Berntsen D, Jacobsen AS. Involuntary (spontaneous) mental time travel into the past and future. Conscious Cogn. 2008;17:1093-104.

17. Blackwell SE. Mental imagery: From basic research to clinical practice. Journal of Psychotherapy Integration. 2019;29:235-47.

18. Holmes EA, Mathews A, Mackintosh B, et al. The causal effect of mental imagery on emotion assessed using pictureword cues. Emotion. 2008;8:395-409.

19. Hammen C. Risk Factors for Depression: An Autobiographical Review. Annu Rev Clin Psychol. 2018;14:1-28.

20. Beck AT. Depression. Clinical, Experimental, and Theoretical Aspects. Philadelphia: Univ. Pa. Press; 1967.

21. Beck AT, Rush AJ, Shaw BF, et al. Cognitive Therapy of Depression. New York: Guilford Press; 1979.

22. Killingsworth MA, Gilbert DT. A wandering mind is an unhappy mind. Science. 2010;330:932-2.

23. Gotlib IH, Joormann J. Cognition and Depression: Current Status and Future Directions. Annu Rev Clin Psychol. 2010;6:285-312.

24. Everaert J, Koster EH, Derakshan N. The combined cognitive bias hypothesis in depression. Clin Psychol Rev. 2012;32:413-24.

25. Craske MG, Rauch SL, Ursano R, et al. What is an anxiety disorder? Depress Anxiety. 2009;26:1066-85.

26. Morina N, Deeprose C, Pusowski C, et al. Prospective mental imagery in patients with major depressive disorder or anxiety disorders. J Anxiety Disord. 2011;25:1032-7.

27. Holmes EA, Blackwell SE, Burnett HS, et al. Mental Imagery in Depression: Phenomenology, Potential Mechanisms, and Treatment Implications. Annu Rev Clin Psychol. 2016;12:249-80.

28. Holmes EA, Lang TJ, Deeprose C. Mental Imagery and Emotion in Treatment across Disorders: Using the Example of Depression. Cognitive Behaviour Therapy. 2009a;38:21-8.

29. Bullock G, Newman-Taylor K, Stopa L. The role of mental imagery in non-clinical paranoia. J Behav Ther Exp Psychiatry. 2016;50:264-8.

30. Waytz A, Hershfield HE, Tamir DI. Mental simulation and meaning in life. J Pers Soc Psychol. 2015;108:336-55.

31. Murphy SE, O'Donoghue MC, Blackwell SE, et al. Increased rostral anterior cingulate activity following positive mental imagery training in healthy older adults. Social Cognitive Affective Neuroscience. 2017;12:1950-8.

32. O'Donnell C, Di Simplicio M, Brown R, et al. The role of mental imagery in mood amplification: An investigation across subclinical features of bipolar disorders. Cortex. 2018;105:104-17.

Page 14/18 
33. Lopez-Perez B, Deeprose C, Hanoch Y. Prospective mental imagery and its link with anxiety and depression in prisoners. PLoS One. 2018;13:e0191551.

34. MacLeod AK, Tata P, Tyrer $\mathrm{P}$, et al. Hopelessness and positive and negative future thinking in parasuicide. Br J Clin Psychol. 2005;44:495-504.

35. Sit HF, Hall BJ, Wang Y, et al. The effect of positive mental imagery training on Chinese University students with depression: A pilot study. Current Psychology 2020.

36. Meevissen YM, Peters ML, Alberts HJ. Become more optimistic by imagining a best possible self: effects of a two week intervention. J Behav Ther Exp Psychiatry. 2011;42:371-8.

37. Grol M, Vingerhoets G, De Raedt R. Mental imagery of positive and neutral memories: A fMRI study comparing field perspective imagery to observer perspective imagery. Brain Cogn. 2017a;111:13-24.

38. Grol M, Vanlessen N, De Raedt R. Feeling happy when feeling down: The effectiveness of positive mental imagery in dysphoria. J Behav Ther Exp Psychiatry. 2017b;57:156-62.

39. Marks DF. Visual imagery differences in the recall of pictures. Br J Psychol. 1973;64:17-24.

40. Beck AT, Steer RA, Brown GK. Manual for the Beck Depression Inventory-II. San Antonia: Psychological Corporation; 1996.

41. Yang W, Wu D, Peng F. Application of Chinese version of Beck depression inventory-if to Chinese first-year college students. Chinese Journal of Clinical Psychology. 2012;6:762-4.

42. Qiu L, Zheng X, Wang Y. Revision of the positive affect and negative affect Scal. Chinese Journal of Applied Psychology. 2008;17:550-1.

43. Watson D, Clark LA, Tellegen A. Development and validation of brief measures of positive and negative affect: the PANAS scales. J Pers Soc Psychol. 1988;54:1063-70.

44. Spielberger CD, Gorsuch RL, Lushene R, et al. Manual for State-Trait Anxiety Inventory. Palo Alto: Consulting Psychologists Press; 1983.

45. Wenzlaff RM, Bates DE. Unmasking a cognitive vulnerability to depression: how lapses in mental control reveal depressive thinking. J Pers Soc Psychol. 1998;75:1559-71.

46. Stöber J. Prospective cognitions in anxiety and depression: replication and methodological extension. Cognition Emotion. 2000;14:725-9.

47. Murphy SE, Clare O'Donoghue M, Drazich EH, et al. Imagining a brighter future: the effect of positive imagery training on mood, prospective mental imagery and emotional bias in older adults. Psychiatry Res. 2015;230:36-43.

48. Holmes EA, Mathews A. Mental imagery in emotion and emotional disorders. Clin Psychol Rev. 2010;30:349-62.

49. Saulsman LM, Ji JL, McEvoy PM. The essential role of mental imagery in cognitive behaviour therapy: What is old is new again. Australian Psychologist. 2019;54:237-44.

50. Renner F, Murphy FC, Ji JL, et al. Mental imagery as a "motivational amplifier" to promote activities. Behav Res Ther. 2019;114:51-9.

51. Wilson AC, Schwannauer M, McLaughlin A, et al. Vividness of positive mental imagery predicts positive emotional response to visually presented Project Soothe pictures. Br J Psychol. 2018;109:259-76.

52. Holmes EA, Coughtrey AE, Connor A. Looking at or through rose-tinted glasses? Imagery perspective and positive mood. Emotion. 2008a;8:875-9.

53. Blackwell SE, Rius-Ottenheim N, Schulte-van Maaren YWM, et al. Optimism and mental imagery: A possible cognitive marker to promote wellbeing? Psychiatry Res. 2013;206:56-61.

54. Ji JL, Holmes EA, Blackwell SE. Seeing light at the end of the tunnel: Positive prospective mental imagery and optimism in depression. Psychiatry Res. 2017;247:155-62.

55. Renner F, Ji JL, Pictet A, et al. Effects of Engaging in Repeated Mental Imagery of Future Positive Events on Behavioural Activation in Individuals with Major Depressive Disorder. Cognit Ther Res. 2017;41:369-80.

Page 15/18 
56. Holmes EA, Geddes JR, Colom F, et al. Mental imagery as an emotional amplifier: application to bipolar disorder. Behav Res Ther. 2008;46:1251-8.

57. Renner F, Holmes E Mental Imagery in Cognitive Therapy Research and Examples of Imagery-Focused Emotion, Cognition, and Behavior Change. Science and Practice in Cognitive Therapy Foundations, Mechanisms, and Applications. 2018.

58. Clarke PJF, Nanthakumar S, Notebaert L, et al. Simply Imagining Sunshine, Lollipops and Rainbows Will Not Budge the Bias: The Role of Ambiguity in Interpretive Bias Modification. Cognitive Therapy Research. 2014;38:120-31.

59. Holmes EA, Mathews A, Dalgleish T, et al. Positive interpretation training: effects of mental imagery versus verbal training on positive mood. Behav Ther. 2006;37:237-47.

\section{Figures}

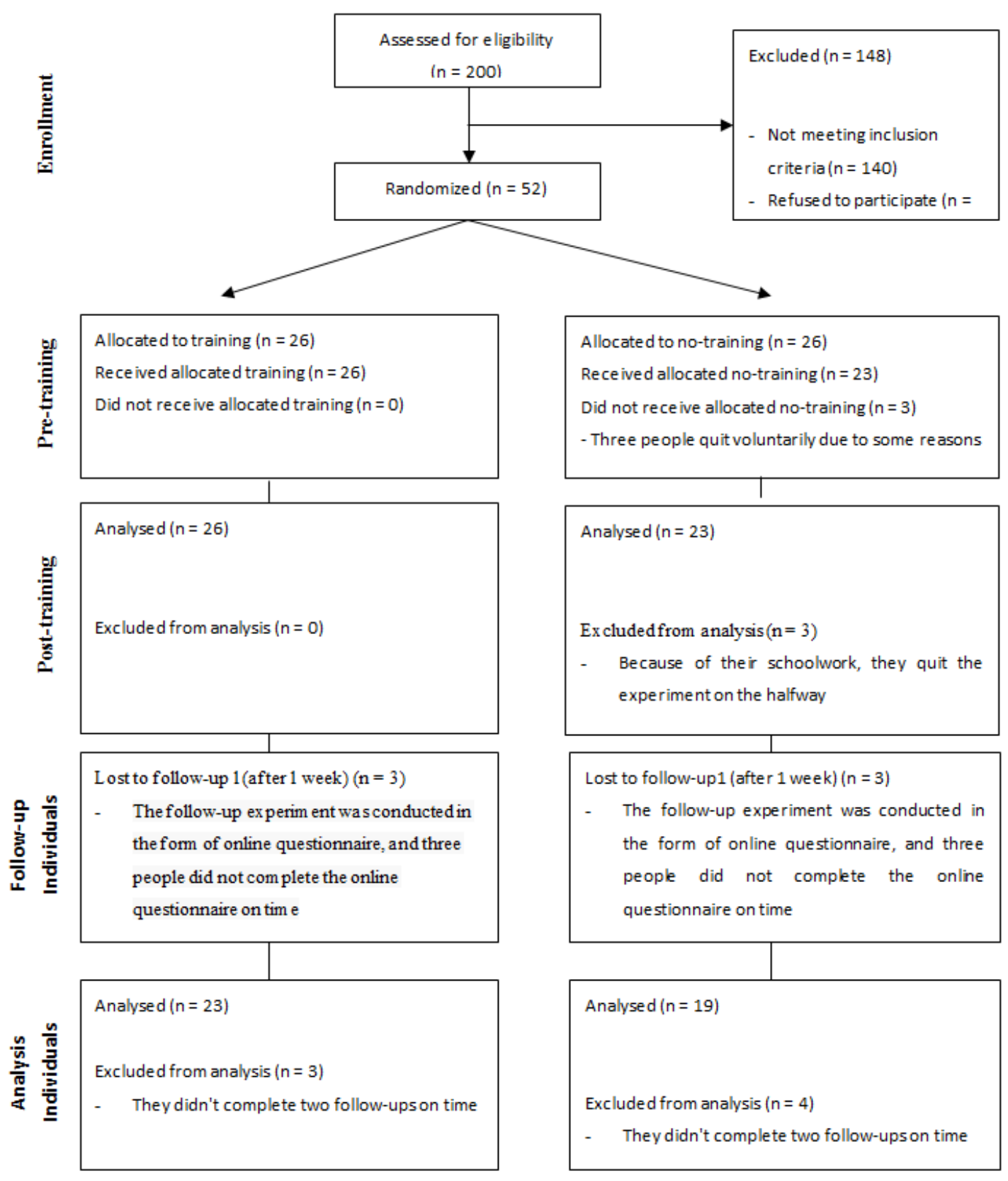

Figure 1 


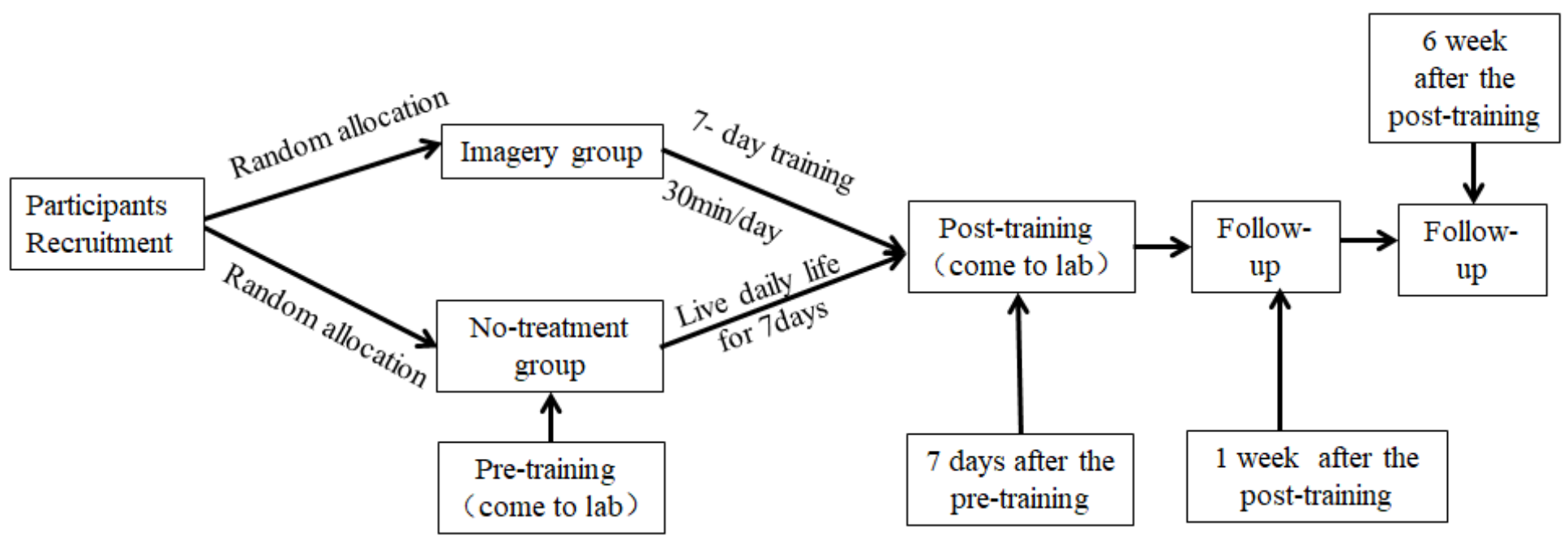

Figure 2

Training Flowchart.

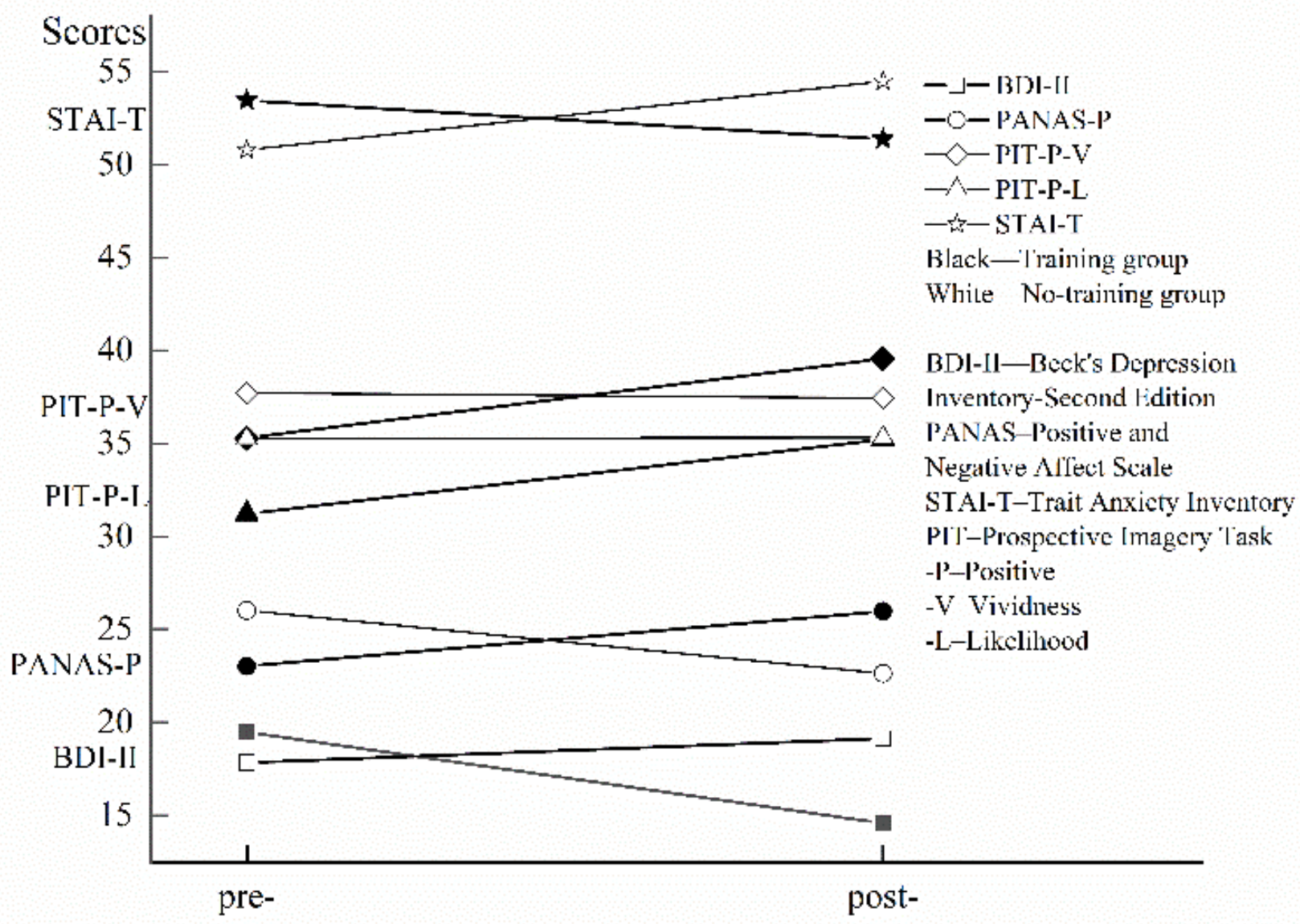

Figure 3 
The interactions between time and group on different variables.
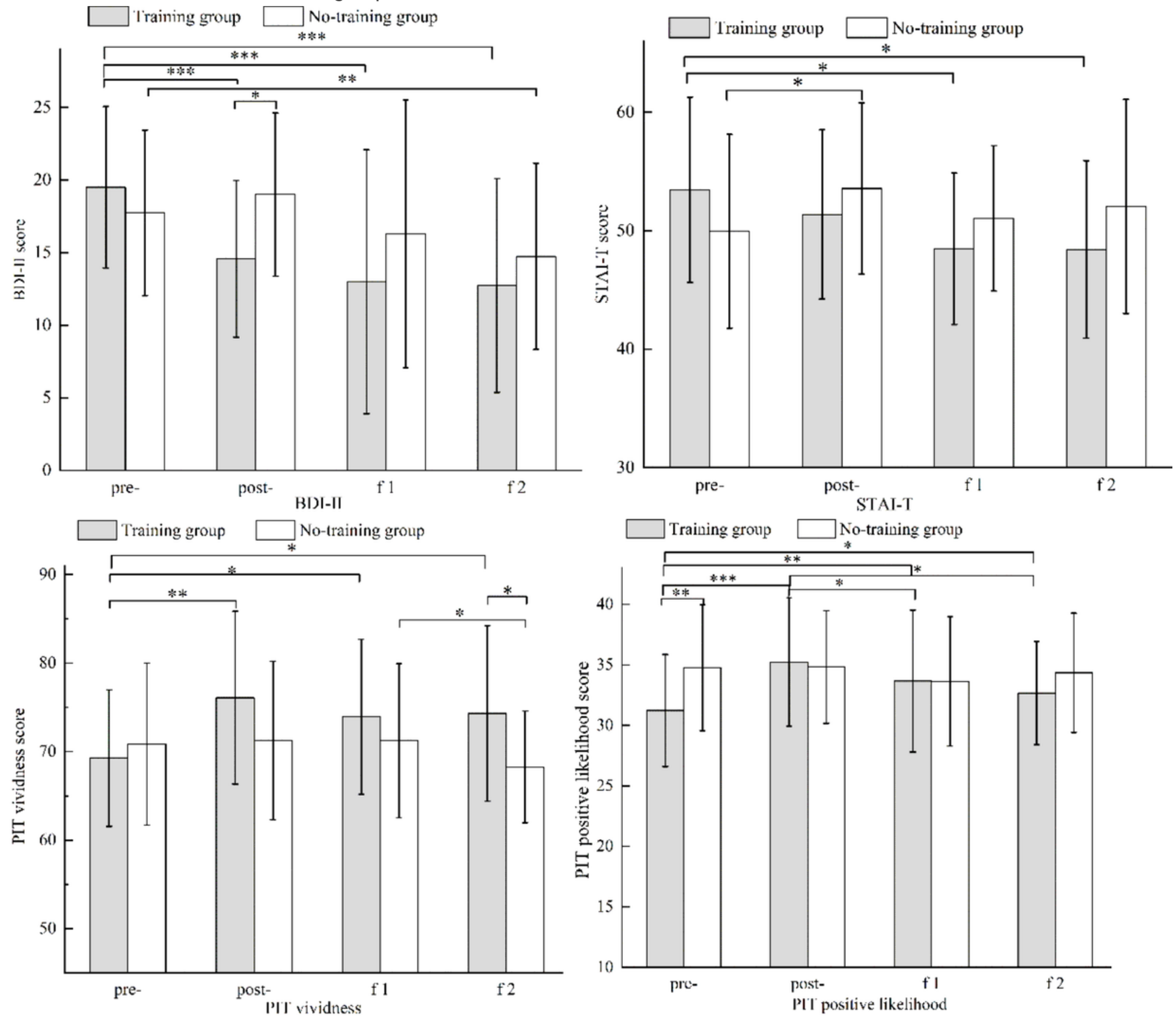

Figure 4

The different measures at 4 time point assessments. Notes: pre-: pre-training; post-: post-training; $f$ 1: after 1-week post-

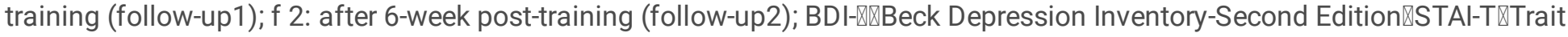
Anxiety Inventory $\triangle \mathrm{PIT}$ : Prospective imagery task

\section{Supplementary Files}

This is a list of supplementary files associated with this preprint. Click to download.

- Checklist.docx

- CONSORTFlowDiagram.doc 